\title{
PCR identification of genes of resistance to black rot in white cabbage using SSR-markers
}

\author{
Yuliya Makukha* \\ Federal Scientific Rice Centre, bldg. 3, Belozerny, Krasnodar, 350921, Russia
}

\begin{abstract}
The present study revealed the polymorphism of SSR loci by the resistance of white cabbage to black rot in contrasting isogenic samples of white cabbage. 2 informative SSR markers were selected: O110-C01 and O111-H06 for ranking breeding samples based on resistance to Xanthomonas campestris pv. campestris Dows. The microsatellite marker O110-C01 was tested on breeding samples and reveals polymorphism between them; therefore, it can be recommended for practical breeding for programs to develop black rot-resistant hybrids of cabbage, which will solve the problem of import substitution and healthy food (environmentally friendly products, grown without the use of means of chemical protection).
\end{abstract}

\section{Introduction}

White cabbage is one of the most common vegetable crops; it is cultivated from polar to subtropical regions and takes one of the first places in Russia in terms of gross harvest. [1]. Various pathogens, including bacterial ones, negatively affect the productivity of cabbage crops. Black rot of white cabbage caused by the gram-negative bacterium Xanthomonas campestris pv. campestris (Pam.) Dowson, is one of the most fatal diseases, leading to a decrease in yield under conditions favorable for the pathogen to $50 \%[2,3]$. Controlling the spread of the disease is very difficult, as $X$. campestris spreads through insects, wind, irrigation and agricultural work $[4,5]$. Therefore, the cultivation of resistant varieties of white cabbage is one of the effective approaches in breeding to minimize yield losses due to exposure to the pathogen. [6].

The use of DNA marking in this direction will significantly reduce labor costs and accelerate the breeding process, thereby controlling the transfer of Xcc resistance genes from one organism to another [7]. This practice has already been successfully implemented in many other important crops, such as rice. [8]. To date, some scientists have already conducted a series of studies on the identification of genes for resistance to black rot, as well as the study of the racial composition of the pathogen. So, at first five races of the pathogen were isolated, later their number increased to eleven [9], of which the races Xcc 1 and 4 are considered the most harmful. Sources of resistance to the main afflicting Xcc

\footnotetext{
*Corresponding author: makyxa69@mail.ru
} 
races (1 and 4) are mainly associated with A and B genomes (B. rapa u B. nigra) and are rarely found in genome $C$ (B. oleracea) [10]. Molecular maps of the B. oleracea genome were independently developed by several research groups using different types of markers (RAPD, SSR, ISSR, dCAPS, SNP) [6, 11-14] Genes and QTL of resistance to the most pathogenic races 1 and 4 were identified on different chromosomes (linkage groups). For example, in Lee's work (2015), in eight out of nine chromosomes in B. oleracea a total of 14 QTL associated with $X c c$ resistance were mapped, four of which belonged to the main loci that affect plant resistance, which led to the conclusion that control of this trait in $B$. oleracea is polygenic [13]. Molecular markers closely linked to them and associated with resistance have been identified for a number of genes and QTL of resistance. In the work of Afrin et al. (2018) some of these markers (9 SSR and 1 InDel) were tested on 27 inbred cabbage lines resistant to different pathogen races [4]. Comparison of molecular screening and phytopathological tests allowed us to select five markers capable of distinguishing resistant forms from those affected. We also studied the expression of NBS-containing sequences in resistant to $X c c$ and in affected cabbage lines in various plant tissues (leaves, roots, xylem, stem). Comparison of the locus sequences in resistant and afflicted forms revealed several indels and SNP variants that can be used in the development of markers for molecular screening [15].

Currently, there are no universal markers of resistance loci to provide a high and reliable assessment of the identification of black rot resistance genes. Therefore, the search for resistance genes to $X$. campestris and the development of informative molecular markers to accelerate and increase the efficiency of breeding process for resistance to the black rot causative agent remains relevant.

\section{Materials and methods}

This study was conducted on the basis of the laboratory of information, digital and biotechnologies of FSBSI ARRRI in 2019. The study material was contrasted forms of white cabbage (9 resistant and 9 susceptible to black rot plants), as well as breeding samples of white cabbage, selected in the department of vegetable and potato breeding of FSBSI "Federal Scientific Rice Centre". DNA from cabbage leaves was isolated by the standard $\mathrm{CTAB}$ method according to Murray and Thompson [16] using cetyltrimethylammonium bromide (CTAB) as the main lysis buffer.

During DNA analysis, neutral codominant microsatellite (SSR) markers were used, taken from the database on the website www.VegMarks.ru, designed to assess the level of polymorphism in Brassica oleraceae L. plants. The used primers were synthesized by Syntol CJSC (Moscow). Their sequence is presented in table 1.

Table 1. The nucleotide sequence of the primers for B. oleracea

\begin{tabular}{|l|l|}
\hline \multicolumn{1}{|c|}{ Primer name } & \multicolumn{1}{c|}{ Primer Sequence Design } \\
\hline AF458409 & $\begin{array}{l}\text { F- AGAAAGCAGACGGGAATGG } \\
\text { R- TGGTTAAAGCGAAAGTGTGC }\end{array}$ \\
\hline BZ523957 & $\begin{array}{l}\text { F- ATTATGACGCCTGGTTTTA } \\
\text { R- TTGGTTAGAAGTTATGGGAAC }\end{array}$ \\
\hline CC969431 & $\begin{array}{l}\text { F- AAGCCACCTCACCTTAGCC } \\
\text { R- GAAATCCCAGAGACTGAAAACC }\end{array}$ \\
\hline CC969459 & $\begin{array}{l}\text { F- CCAAAGATTCAGAGGAAATGG } \\
\text { R- GCGTCAAAAACGGTGTCG }\end{array}$ \\
\hline O110-B04 & $\begin{array}{l}\text { F- ATCTTCCTCCACGTTCATGC } \\
\text { R- CGAATCTTGAAGTTCTGACCC }\end{array}$ \\
\hline
\end{tabular}


Continuation of the table 1

\begin{tabular}{|c|c|}
\hline O110-B08 & $\begin{array}{l}\text { F- AAGCTGTTCGATGAAATGCC } \\
\text { R- ACTTGTTTGCATCCATTGCC }\end{array}$ \\
\hline Ol10-C01 & $\begin{array}{l}\text { F- ATGACTGCTTAAACAGCGCC } \\
\text { R- CTTCTCCAACAAAAGCTCGG }\end{array}$ \\
\hline O110-C10a & $\begin{array}{l}\text { F- AAGAAGGCGTAGAGATTGCC } \\
\text { R- GCAGATAAGATTCGAGTCCCC }\end{array}$ \\
\hline $\mathrm{O} 110-\mathrm{C} 10 \mathrm{~b}$ & $\begin{array}{l}\text { F- AAGAAGGCGTAGAGATTGCC } \\
\text { R- GCAGATAAGATTCGAGTCCCC }\end{array}$ \\
\hline Ol10-D01 & $\begin{array}{l}\text { F- TCTCTGCCAAAAGCAAATAGC } \\
\text { R- CTTGGCTCTCTCTCACCACC }\end{array}$ \\
\hline Ol10-D02 & $\begin{array}{l}\text { F-CATTTCTCAATGATGAATAGTTTTGG } \\
\text { R- CCATTGATATGGAGATGGGG }\end{array}$ \\
\hline Ol10-D08 & $\begin{array}{l}\text { F- TCCGAACACTCTAAGTTAGCTCC } \\
\text { R- GAGCTGTATGTCTCCCGTGC }\end{array}$ \\
\hline O110-F06 & $\begin{array}{l}\text { F- CATTGGTTTAGTCATTTCGTCG } \\
\text { R- AATTCAAAAACTGCCGAACG }\end{array}$ \\
\hline O110-G05 & $\begin{array}{l}\text { F- TCAATGCTCTTGTAGTCTTTGACC } \\
\text { R- AGAATGAGAGCGTGGAGAGG }\end{array}$ \\
\hline O111-B05 & $\begin{array}{l}\text { F- TCGCGACGTTGTTTTGTTC } \\
\text { R- ACCATCTTCCTCGACCCTG }\end{array}$ \\
\hline Ol11-H06 & $\begin{array}{l}\text { F- TCCGAACACTCTAAGTTAGCTCC } \\
\text { R- TTCTTCACTTCACAGGCACG }\end{array}$ \\
\hline Ol11-H09 & $\begin{array}{l}\text { F- CCCTTTTCCCCTTCTATTGG } \\
\text { R- GTGCGACTTGGAATTTCTCC }\end{array}$ \\
\hline O112-A04 & $\begin{array}{l}\text { F- TGGGTAAGTAACTGTGGTGGC } \\
\text { R- AGAGTTCGCATACTCTGGAGC }\end{array}$ \\
\hline Ol12-G04 & $\begin{array}{l}\text { F- CGAACATCTTAGGCCGAATC } \\
\text { R- GGTTAACCTGCGGGATATTG }\end{array}$ \\
\hline $\mathrm{O} 113-\mathrm{C} 12$ & $\begin{array}{l}\text { F- AGAGGCCAACAAAGAACACC } \\
\text { R- GAAGCAGCACCAGTGACAAG }\end{array}$ \\
\hline
\end{tabular}

Amplified DNA fragments were separated using a $2 \%$ agarose gel with the addition of ethidium bromide at a voltage of $120 \mathrm{~V}$ for 1 hour and photographed in ultraviolet light.

\section{Results and discussion}

During the molecular genetic study, 20 neutral microsatellite markers localized on different chromosomes were tested on the forms of white cabbage contrasting in terms of resistance to black rot, 2 of which revealed polymorphism (allelic difference) between the studied samples. The results of testing these markers are presented in figures 1,2 .

On the electrograph, the allelic difference between the stable and unstable genotypes (isogenic lines) is clearly visible. The donor allele has a PCR product size of 217 base pairs (bp), the recessive allele has 222 base pairs, which allows the use of this marker for ranking genotypes by disease resistance. Figure 2 shows the results of PCR analysis at the O111H06 locus. 


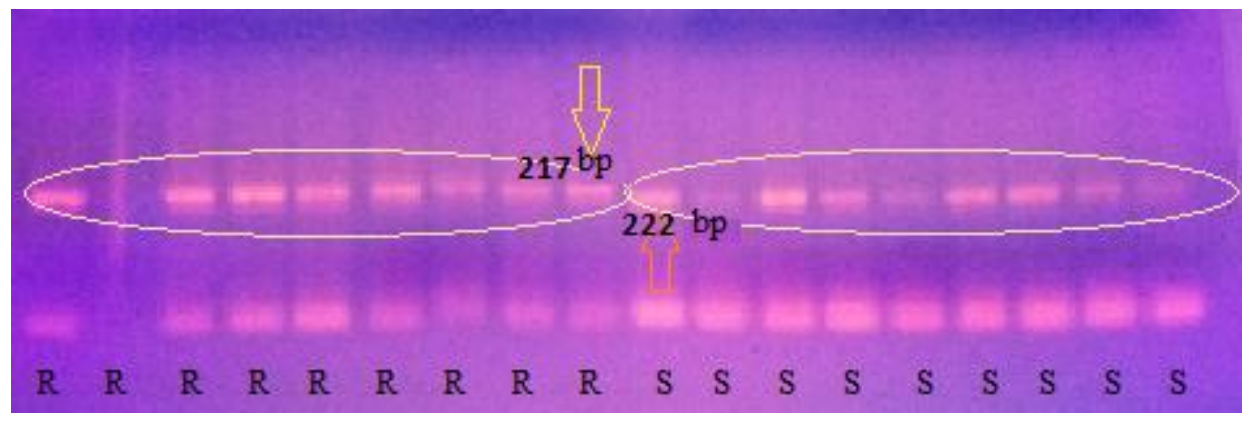

$\mathrm{R}$ (Resistant) - resistant isogenic line 12-1;

$\mathrm{S}$ (Susceptible) - non-resistant isogenic line 12-2.

Fig. 1. Visualization of PCR products at the locus O110-C01 in a $2 \%$ agarose gel

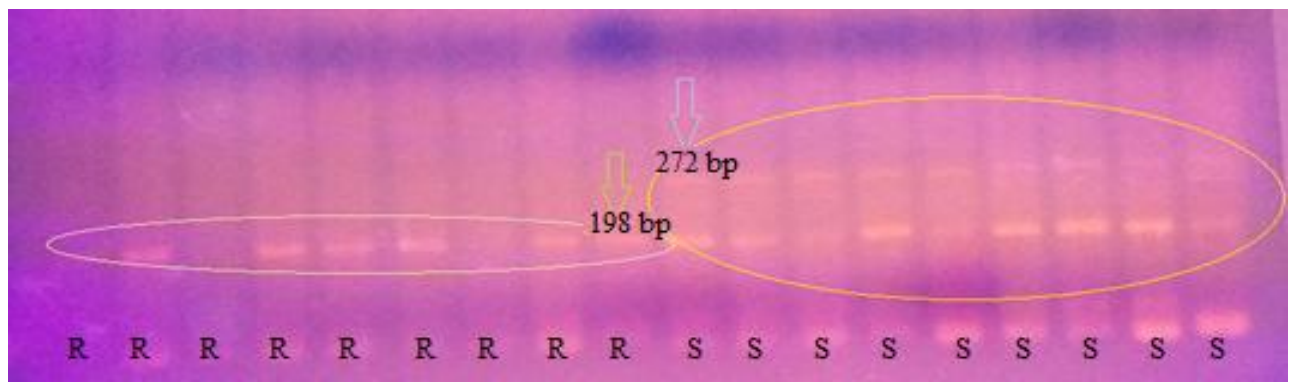

$\mathrm{R}$ (Resistant) - resistant isogenic line 12-1;

$\mathrm{S}$ (Susceptible) - non-resistant isogenic line 12-2.

Fig. 2. Visualization of PCR products at the locus Ol11-H06 in a $2 \%$ agarose gel

Figure 2 shows the allelic difference between the studied isogenic lines of Brassica oleracae L., contrasting in resistance to black rot. The donor allele has PCR - product with a size of $198 \mathrm{bp}$, a recessive one - $272 \mathrm{bp}$, which will also allow the use of this marker for ranking the analyzed hybrids of white cabbage on the basis of resistance to Xanthomonas campestris. When studying the remaining 18 markers, the allelic difference between contrast forms was not found.

Subsequently, one of the selected markers O110-C01 was tested on breeding samples of white cabbage, as it reveals the greatest polymorphism between forms of contrasting resistance and allows you to visually evaluate the studied genotypes on an electrophoregram. Using this marker on the basis of the PCR method, samples of plants of the F1 generation hybrid combination 269-Яс12п-2 х Пи714 and isogenic line 269-Яс12п$2 \times$ Пи714 were analyzed. The results of molecular genetic research of these samples of cabbage plants are presented in Figures 3, 4 . 


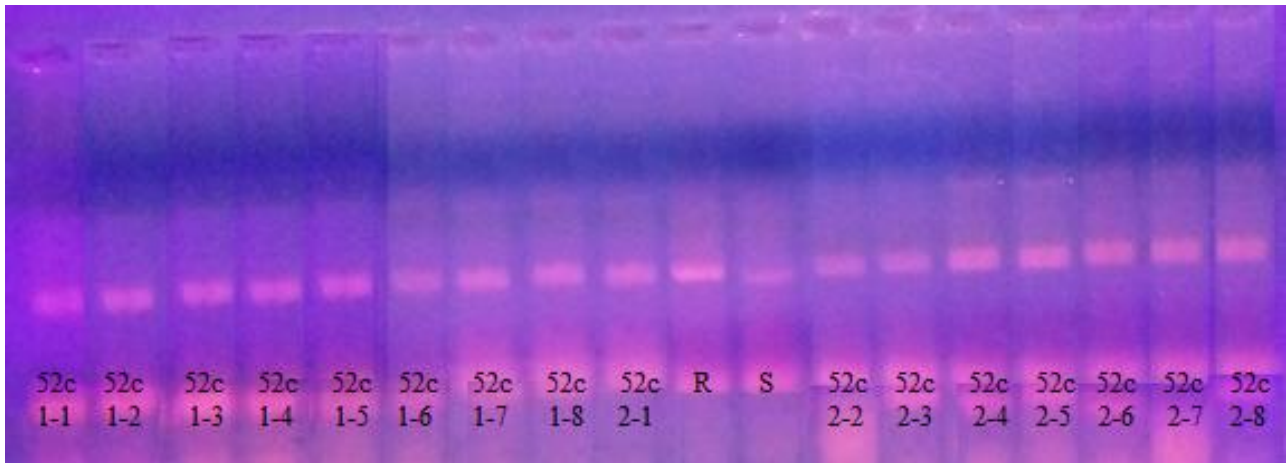

52c 1-1 - 52c 2-8 - plant samples of white cabbage F1 generation from hybrid combination 269-Yas12p-2 x Pi714;

$\mathrm{R}$ (Resistant) - resistant isogenic line 269-Yas12p-2;

$\mathrm{S}$ (Susceptible) - non-resistant isogenic line Pi714.

Fig. 3. Separation of plant amplification products of a hybrid combination 269-Yas12p-2 x Pi714 at the locus O110-C01

Figure 3 shows that the analyzed samples of cabbage have alleles of resistance and susceptibility, i.e. are heterozygotes for this characteristic, which corresponds to Mendel's law on the uniformity of first-generation hybrids.

Figure 4 shows the results of a PCR analysis with this microsatellite marker of plant samples of cabbage of isogenic line 269-Yas12p 2.

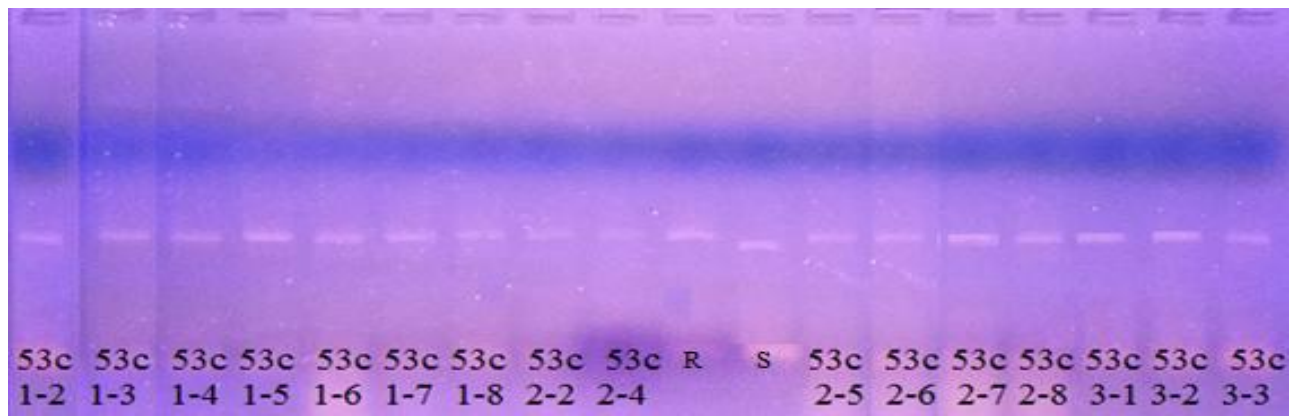

53c 1-2 - 53c 3-3 - white cabbage plants of isogenic line 269-Yas 12p-2;

$\mathrm{R}$ (Resistant) - resistant isogenic line 12-1;

$\mathrm{S}$ (Susceptible) - non-rsistant isogenic line Pi714.

Fig. 4. Separation of products of plant amplification of the isogenic line $269-Y a s 12 p-2$ at the locus Ol10-C01

From the presented electrophoregram in Figure 4, it can be seen that all the analyzed plants of the isogenic line 269-Yas12p-2 have only the donor resistance allele in the genotype, i.e. are homozygotes for the recessive allele, which is confirmed by the phytopathological test in the department of vegetable and potato breeding. 


\section{Conclusions}

According to the results of the study, the O110-C01 marker can be involved in a further breeding process to test its effectiveness in identifying the allele of resistance to black rot in subsequent generations of white cabbage and thereby to establish compliance with the Mendel splitting in the offspring on this basis.

\section{References}

1. F.A. Berensen, O. Yu. Antonova, A.M. Artemyeva, Vavilov Journ.of Gen. and Breed. 23(6), 656-666 (2019) https://doi.org/10.18699/VJ19.538.

2. B.B. Sharma, P. Kalia, D.K. Yadava, D. Singh, T.R. Sharma, PLoS ONE 11(3) (2016) https://doi.org/10.1371/journal.pone.0152290.

3. S. Singh, S.S. Dey, R. Bhatia, J. Batley, R. Kumar, Euphytica 214 (2018) https://doi.org/10.1007/s10681-018-2275-3

4. K.S. Afrin, M.A. Rahim, J. Park, S. Natarajan, M.H. Rubel, H. Kim, I. Nou, Plant Breed. Biotech. 6(1), 30-43 (2018) https://doi.org/10.9787/PBB.2018.6.1.30

5. B.B. Sharma, P. Kalia, D. Singh, T.R. Sharma, Front. Plant Sci. 8: 1255 (2017) https://doi.org/10.3389/fpls.2017.01255.

6. N.N. Tonu, M.A. Doullah, M. Shimizu, M.M. Karim, T. Kawanabe, R. Fujimoto, K. Okazaki, American Journal of Plant Sciences 4, 11-20 (2013) http://dx.doi.org/10.4236/ajps.2013.48A002

7. E.V. Dubina, V.N. Shilovsky, P.I. Kostylev, M.G. Ruban, A.M. Ogly, Plant Biotech. and Breed.2(1) (2019) https://doi.org/10.30901/2658-6266-2019-1-16-23

8. E.V. Dubina, A.V. Alabushev, P.I. Kostylev, Yu.A. Makukha, M.G. Ruban, I.V. Balyasnyi, Le.H. Ham, D.X. Tu, Le.H. Linh, African Journ. of Agricult. Research 13(48), 2757-2762 (2018) https://doi.org/10.5897/AJAR2018.13563.

9. J. Cruz, R.Tenreiro, L. Cruz J., Plant Pathol. 9, 403-414 (2017) https://doi.org/10.4454/jpp.v99i2.3890.

10. J.G.Vicente, E.B. Holub, Mol. Plant Pathol. 14(1), 2-18 (2013) https://doi.org/10.1111/j.1364-3703.2012.00833.x.

11. Y. Kifuji, H. Hanzaea, Y. Terasawa, T. Nishio, Euphytica 190, 289-295 (2013) https://doi.org/10.1007/s10681-012-0847-1.

12. P. Saha, P. Kalia, M. Sharma, D. Singh, Euphytica 2016 207, 35-48 (2016) https://doi.org/10.1007/s10681015-1524-y.

13. J. Lee, N.K. Izzah, V. Jayakodi, S. Perumal, H.J. Joh, H.J. Lee, S. Lee, J.Y. Park, K. Yang, I. Nou, J. Seo, J. Yoo, Y. Suh, K. Ahn, J.H. Lee, G.J. Choi, Y. Yu, H. Kim, T. Yang, BMC Plant Biol. 15(32) (2015) https://doi.org/10.1186/s12870-015-0424-6.

14. L. Iglesias-Bernabé, P. Madloo, V.M. Rodríguez, M. Francisco, P. Soengas, Sci. Rep. 9 (2019) https://doi.org/10.1038/s41598-019-38527-5.

15. K.S. Afrin, M.A. Rahim, J. Park, S. Natarajan, H. Kim, I. Nou, Mol. Biol. Rep. 45(5), 773-785 (2018b) https://doi.org/10.1007/s11033-018-4217-5.

16. J.F. Li, L. Li, J. Sheen, January 2010Plant Methods 6(1) (2010) http://dx.doi.org/10.1186/1746-4811-6-1 